\title{
Online Tourism Product Information Concern and Purchase Intention
}

\author{
Tu Wei \\ Institute of Tourism and Society Management, NanJing Xiao Zhuang University, Hongjing road, NanJing, \\ China
}

Keywords: Online tourism route; Information concern; Purchase intention; Influence

\begin{abstract}
Online tourism information concern and product reservation have become the hot issues of online tourism research. With the help of factor analysis and structural equation model, this paper analyzes the characteristics of tourists' attention to online tourism route product information and its influence on their purchase intention. The results show: (1) Tourists pay attention to online tourism product information, which includes four dimensions: general elements of tourism products, comprehensive marketing elements, safe and efficient channels, and traditional marketing elements. Tourists are most concerned about the general elements of tourism products and traditional marketing elements. (2) There is a significant positive correlation between the general elements of tourism products, comprehensive marketing elements and tourists' willingness to buy. Moreover, there is a significant negative correlation between traditional marketing factors and tourists' willingness to buy. (3) When tourists buy online tourism products, they consider suppliers, the number of days of tourism routes, price, number of route purchases. Tourists are becoming more rational and cautious in purchasing low-cost tourism route products.
\end{abstract}

\section{Introduction}

China Internet Network Information Center (CNNIC)'s 44th Statistical Report on Internet Development in China in August 2019 shows that the scale of Chinese Internet users has reached 854 million, accounting for one fifth of the total number of Internet users worldwide. With the popularity of the Internet, the influence of the Internet on tourism behavior continues to emerge. The proportion of tourists using the Internet for tourism information search and travel booking keeps increasing, and the online information concern and purchase decision of tourists have become one of the hot issues in tourism behavior research.

\section{Literature Review}

Marketing master Philip Kotler proposed the theory of consumer purchase decision process. He believes that consumers' purchase decision needs to go through five stages: cognition, information search, program evaluation, purchase decision and post-purchase evaluation. It can be seen that information search and attention are important links in consumer product purchase decisions, and also one of the important contents of consumer behavior research. Foreign scholars have found that tourists want to get information about flights, accommodation, car rental, scenic spots introduction, cruise, weather, tourism guide, train tickets, customs and folk customs from tourism websites when making tourism decisions [1-2]. Choi's research is more in-depth, he found that tourists before, during and after the trip to pay attention to and search for tourism information is different, tourists before the trip mainly search for accommodation, air tickets, weather or travel advice, maps or driving guide, attractions, popular travel information and large-scale activities and other information; Search for information such as weather or travel advice, maps or driving guides, events and restaurants during the trip; At the end of the trip, travelers will share their experiences [3]. Domestic scholars' research shows that the degree of tourists' attention to network information has obvious hierarchy [4]. The most important thing for tourists is the core tourism information, followed by auxiliary tourism information and internet word-of-mouth information. The core tourism information involves the three core elements of "transportation", "accommodation" and 
"play", and the auxiliary tourism information involves the three tourism elements of "shopping", "entertainment" and "eating” [5]. Online tourism information can influence the purchasing behavior of users, thus influencing the sales volume of products. A large number of literature at home and abroad are exploring the influence factors of online purchase intent and booking behavior of tourists. Internet user reviews or word-of-mouth [6-7]; prices and discounts [8-10]; website quality [11-12]; personal factors [13-14]; perceived risks and value of tourists during the booking process [15]-[16] have influence on tourists' online purchase decision behavior to varying degrees. The academic circle has further refined the research on the types of online purchase of tourism products. Some scholars have conducted a lot of research on hotel product booking [17-21], and found that the online booking rate of hotel products is higher than that of tourism products [22]. However, scholars pay less attention to the travel route products launched by travel agencies or online travel service providers on the Internet, focusing mostly on the design of the travel route [23-24], the network space structure of the travel route [25-26], and the travel flow brought by the travel route [27-28], while paying less attention to the booking behavior of tourists' online tourism route. With the rise and development of online tourism e-commerce website, the attention and booking of online tourism route product information has become an important part of tourists' online tourism consumption decision-making. Therefore, it is necessary to study the online tourism route product information concern and booking behavior of tourists. This paper takes the tour route buyers of Tu Niu and Tong Cheng as the research object, studies the characteristics of online tourism route product information concert and its influence on online purchase intent, so as to serve for the construction of online tourism route product information of tourism enterprises.

\section{Data and Questionnaire Design}

The data comes from the customer survey of two major travel websites, Tu Niu and Tong Cheng. Each website surveyed 200 questionnaires, a total of 400 questionnaires. The follow-up survey was conducted by tourists who have purchased travel route products on the two major websites. The questionnaire was issued in October 2019. The questionnaire was mainly issued in two ways, one was electronic Mail; the second is telephone access. Due to the difficulty in recovering E-mail, some questionnaires were not collected in time. In the end, 376 questionnaires were collected, with a recovery rate of $94 \%$, and 350 valid questionnaires, with an effective rate of $93 \%$. The design of the questionnaire is divided into three parts, with a total of 32 indicators. The first part consists of four indicators, which are basic information about tourists, including residence, gender, age and monthly income. In the second part, there are 25 indicators, which are tourists' information concern indicators for online tourism route products. The 25 indicators are respectively named as X1 focuses on website security, X2 focuses on website popularity, X3 focuses on tourism route information, X4 focuses on tourism route schedule days, X5 focuses on tourism route cities, X6 focuses on the period of validity of tourism route products, $\mathrm{X} 7$ on the short-term tourist line products, X8 on the tourism resources in tourist line products, X9 on the inner city tourist lines, $\mathrm{X} 10$ on the high-priced tourist lines, X11 on the brand tourism resources in tourism routes, X12 focuses on beautiful pictures of tourism routes, X13 focuses on tourism information and provides very rich tourism route products, X14 focuses on tourism route product prices, X15 focuses on mid-level hotels, X16 focuses on low-price tourism routes, X17 focuses on medium-price tourism routes, X18 focuses on product discounts of tourism routes, X19 focuses on highly discounted tourism route products, X20 on travel route products with large number of buyers, X21 on long-validity tourism route products, X22 on tourism experience evaluation, X23 on supplier brand, X24 on whether the supplier is my local city, and X25 on hotel factors in the tourism route products; The third part is a total of 3 indicators, which are online shopping purchase intention indicators. They are y1 and online shopping tourism products, and y2 online shopping tourism products make me very satisfied. The questionnaire uses likert scale to ask the respondents to indicate their response to the statement with a scale of 1 (totally disagree) - 5 (totally agree). 


\section{Research and Analysis}

The data comes from the customer survey of two major travel websites, Tu Niu and Tong Cheng. Each website surveyed 200 questionnaires, a total of 400 questionnaires. The follow-up survey was conducted by tourists who have purchased travel route products on the two major websites. The questionnaire was issued in October 2019. The questionnaire was mainly issued in two ways, one was electronic Mail; the second is telephone access. Due to the difficulty in recovering E-mail, some questionnaires were not collected in time. In the end, 376 questionnaires were collected, with a recovery rate of $94 \%$, and 350 valid questionnaires, with an effective rate of $93 \%$. The design of the questionnaire is divided into three parts, with a total of 32 indicators. The first part consists of four indicators, which are basic information about tourists, including residence, gender, age and monthly income. In the second part, there are 25 indicators, which are tourists' information concern indicators for online tourism route products. The 25 indicators are respectively named as X1 focuses on website security, X2 focuses on website popularity, X3 focuses on tourism route information, X4 focuses on tourism route schedule days, X5 focuses on tourism route cities, X6 focuses on the period of validity of tourism route products, $X 7$ on the short-term tourist line products, X8 on the tourism resources in tourist line products, X9 on the inner city tourist lines, $\mathrm{X} 10$ on the high-priced tourist lines, X11 on the brand tourism resources in tourism routes, X12 focuses on beautiful pictures of tourism routes, X13 focuses on tourism information and provides very rich tourism route products, X14 focuses on tourism route product prices, X15 focuses on mid-level hotels, X16 focuses on low-price tourism routes, X17 focuses on medium-price tourism routes, X18 focuses on product discounts of tourism routes, X19 focuses on highly discounted tourism route products, X20 on travel route products with large number of buyers, X21 on long-validity tourism route products, X22 on tourism experience evaluation, X23 on supplier brand, X24 on whether the supplier is my local city, and X25 on hotel factors in the tourism route products; The third part is a total of 3 indicators, which are online shopping purchase intention indicators. They are y1 and online shopping tourism products, and y2 online shopping tourism products make me very satisfied. The questionnaire uses likert scale to ask the respondents to indicate their response to the statement with a scale of 1 (totally disagree) - 5 (totally agree).

\subsection{Sample description}

The sociological characteristics of the investigated group, namely online tourism consumers, were analyzed. The results showed that most of the online tourists came from Jiang Su. This is mainly because the two websites were founded in Jiang Su, Tu Niu was founded in Nanjing in 2006 and Suzhou in 2004. Women are the main buyers of online tourism route products. $83.3 \%$ of the survey population are 20-30 years old, indicating that online tourism route product purchase is still dominated by young people. Online purchase consumers account for a large proportion of monthly income below 3000 , accounting for $55.4 \%$, followed by 3,000-5000, accounting for $37.8 \%$, online consumption is mainly dominated by middle- and low-income earners, which is related to the younger age of online consumers. The percentage of people who purchase online 1-2 times per year is $61.3 \%$. Sociological characteristics suggest that women, young groups and people with low monthly income should be the key groups for online tourism route product marketing. It is very important to find out what information the tourists concern and what drives tourists' buying intentions.

\subsection{Reliability analysis}

Reliability refers to the stability and consistency of questionnaire results when the same method is used to survey the same object, that is, whether the measuring tool (questionnaire or scale) can measure the thing or variable stably. Through the reliability analysis of spss16.0, the overall reliability analysis is performed on 28 indicators of online tourists' attention information and purchasing attitude. The overall reliability of the questionnaire is 0.887 . It shows that the information concern and purchase intention questionnaire composed of 28 indicators have certain credibility. 


\subsection{Exploratory factor analysis}

Exploratory factor analysis was performed on 25 items of information concern variables for online tourism route products. The results showed that $\mathrm{KMO}=0.795$, indicating that it is suitable for factor analysis. In factor analysis, this study uses principal component analysis to extract factors. In order to explain the potential factors, the maximum variance orthogonal rotation method is used. Excluding the observation variables X5 (focusing on the city where the tourist route passes), X6 (focusing on the validity period of the tourist route product), X7 (focusing on the short validity period of the tourist route product), $\mathrm{X} 8$ (focusing on the tourist resources in the tourist route product), $\mathrm{x} 10$ (focusing on the high price tourist route), x15 (focusing on the high-grade hotels in the tourist route product), the remaining 19 indicators are extracted, 4 indicators in total Common factor. All eigenvalues are greater than 1, and the variance contribution rate shows that the 4 common factors cumulatively explained $74.93 \%$ of the information, exceeding the minimum standard of $60 \%$ variance contribution rate. The four common factors are named as general factors of tourism products, comprehensive factors of marketing, factors of channel safety and efficiency, and factors of traditional marketing, as shown in table 1.

Table 1 Information concern factor analysis for online tourism products

\begin{tabular}{|c|c|c|c|}
\hline Factors and variables & Load & $\begin{array}{l}\text { Mean } \\
\text { value }\end{array}$ & $\begin{array}{l}\text { Standard } \\
\text { deviation }\end{array}$ \\
\hline \multicolumn{4}{|l|}{ Factor 1: general elements of tourism products } \\
\hline $\mathrm{x} 1$ : Focus on the number of days of travel products (X4) & 0.62 & 3.55 & 0.79 \\
\hline x2: focus on the price of tourism products (X14) & 0.56 & 3.52 & 0.91 \\
\hline $\begin{array}{l}\text { x3: Focus on tourism products with a longer validity period } \\
\qquad(\mathrm{X} 21)\end{array}$ & 0.55 & 3.29 & 0.98 \\
\hline x4: Focus on supplier branding (X23) & 0.64 & 3.13 & 0.95 \\
\hline $\mathrm{x} 5$ : Focus on whether the supplier is my local city (X24) & 0.44 & 2.80 & 0.86 \\
\hline x6: Focus on hotel factors in tourism products (X25) & 0.57 & 3.02 & 0.94 \\
\hline \multicolumn{4}{|l|}{ Factor 2: comprehensive elements of marketing } \\
\hline x7: Attracted by beautiful tourism resource pictures (X12) & 0.67 & 2.39 & 0.96 \\
\hline x8: Focus on discounts for travel products (X18) & 0.60 & 2.69 & 0.93 \\
\hline x9: Focus on high-discount travel route products (X19) & 0.57 & 2.68 & 0.95 \\
\hline $\begin{array}{c}\text { x10: Tend to choose travel route products with a large } \\
\text { number of purchasers (X20) }\end{array}$ & 0.46 & 2.25 & 1.00 \\
\hline $\begin{array}{l}\text { x11: Focus on the experience evaluation of previously } \\
\text { purchased tourists (X22) }\end{array}$ & 0.47 & 2.27 & 0.99 \\
\hline \multicolumn{4}{|l|}{ Factor 3: fast and safe channel } \\
\hline x12: Focus on website security (X1) & 0.61 & 2.27 & 0.99 \\
\hline x13: Follow the popularity of the website (X2) & 0.77 & 2.38 & 1.04 \\
\hline $\begin{array}{l}\text { x14: Worried that the travel route information on the website } \\
\text { is messy and credibility is not high (X3) }\end{array}$ & 0.61 & 2.87 & 0.98 \\
\hline x15: Focus on city tour routes (X9) & 0.52 & 2.44 & 0.86 \\
\hline $\begin{array}{l}\text { x16: Focus on whether there are brand tourism resources in } \\
\text { the route (X11) }\end{array}$ & 0.62 & 2.49 & 1.06 \\
\hline \multicolumn{4}{|l|}{ Factor 4: traditional marketing elements } \\
\hline $\begin{array}{c}\text { x17: Tend to provide tourist information with a very rich } \\
\text { travel route product (X13) }\end{array}$ & 0.60 & 2.55 & 0.97 \\
\hline x18: Focus on low-priced travel route products (X16) & 0.80 & 2.95 & 0.77 \\
\hline x19: Focused on middle-price travel route products (X17) & 0.66 & 2.67 & 0.90 \\
\hline
\end{tabular}

Note: capital $\mathrm{X}$ refers to the index ranking before the undeleted load is less than 0.4 , and lowercase $\mathrm{X}$ refers to the index reordering after the deleted load is 0.4 .

Factor 1 in table 1 is defined as the general factor of tourism products, because it contains 
indicators such as schedule days, hotels, suppliers and long validity period. This is the general online tourism products information. Factor 2 is defined as a comprehensive marketing element because it includes various online tourism route product promotion means, such as product discount, experience evaluation, beautiful pictures, number of buyers and other indicators, which is an important marketing means for online tourism service providers to strive for online tourists' purchase. Factor 3 is defined as the channel safety and fast factor, because this factor includes indicators such as website security, website popularity and so on. Factor 4 is defined as a traditional marketing factor. Before the promulgation of the tourism law in 2013, travel agencies, online travel service providers and other tourism enterprises mostly attracted tourists to participate in the tourism with low-cost travel routes. When displaying the information of tourist routes, online tourism enterprises often divide a large scenic spot (point) into a number of post-tourism points for introduction, so that tourism consumers feel excellent quality and reasonable price when booking online tourism route products. This marketing method has attracted the attention of tourists, effectively promoting online purchase intention.

We calculate the mean value of the four common factors.The results show: tourists are most concerned about the general elements of the online tourism route product, followed by the traditional marketing elements. Then, the channel safety and fast elements, and finally the comprehensive marketing elements.

\section{Information Concern and Purchase Intention}

\subsection{Research hypothesis}

\subsubsection{General elements of tourism products}

General elements of tourism products refer to the basic attributes of online tourism products, which are composed of six indicators, such as itinerary days, price, long validity period, suppliers and hotels. Zhu Haiyan [30] and other research results show that the quality of the hotel in the travel itinerary will influence tourists to book online travel products. Suppliers will also influence tourists to book online [31]. Research by Kim [32] and others shows that the price is significantly positive for influence consumers' purchase intention. Therefore, the first hypothesis is proposed.

\subsubsection{Comprehensive elements of marketing}

Marketing comprehensive factor is an important means of online tourism marketing. It can promote tourists' travel purchase decisions. It is composed of beautiful pictures, discount, number of buyers and other indicators. Jiang Xiao et al. [33] found that among all kinds of online tourism information, the influence of online reputation on tourists' decision-making is particularly significant. Wang Qiuzhen [34] research found that both price discounts and number of purchases had a significant positive influence on consumer. Song Zhijie et al. [35] research confirmed that the factors of influence consumers' online purchasing decisions mainly include online reviews and sales. Therefore, the second hypothesis is proposed.

\subsubsection{Channel safety and fast elements}

Peng Liang [36] and other studies have shown that website brand is an important factor for influence consumer trust. Scholars [37] believe that good website perception can stimulate customers to generate a positive experience, which in turn leads to purchase intention. Therefore, the third hypothesis is put forward.

\subsubsection{Traditional marketing elements}

Traditional marketing elements consist of focusing on low - price tourism routes, medium - price tourism routes and other indicators. To some extent, Low price and tourism information decomposition display effectively promote the online purchase behavior of tourists. However, with the promulgation of the tourism law in April 2013, tourists are becoming less and less sensitive to the traditional marketing methods of tourism routes. Zheng Shaocheng [9] found that, due to the 
high-risk nature of online tourism products, although discount can reduce the risk of purchase, low price may also cause customers to question the service products. Therefore, the fourth hypothesis is put forward.

Based on the above analysis, we assume the following four relationships, as shown in figure 1. Firstly, there is a positive correlation between general elements of tourism products and purchase intention. Secondly, there is a positive correlation between comprehensive elements of marketing and purchase intention. Thirdly, there is a positive correlation between the safety and fast channel elements and purchase intention. Lastly, there is a negative correlation between traditional marketing elements and purchase intention.

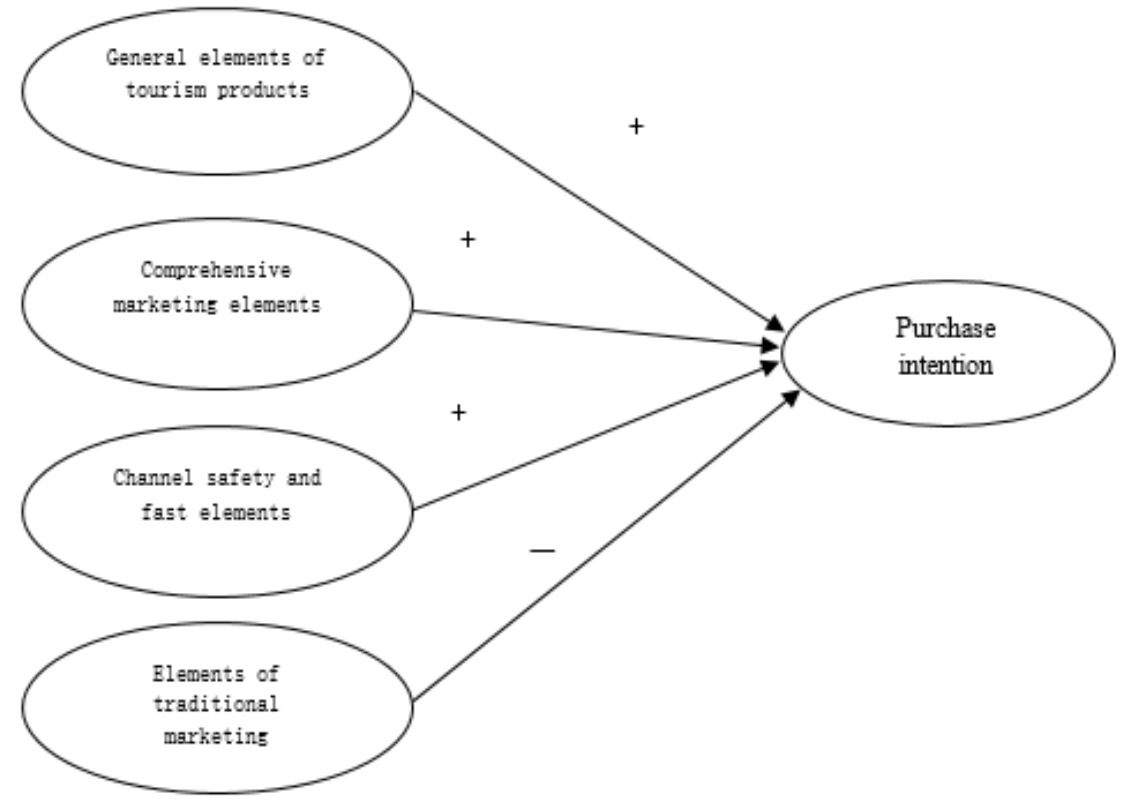

Figure 1 Structure model of the influence of online tourism product information attention on purchase intention

\subsection{Model fit test}

Five potential variables (4 endogenous latent variables, 1 exogenous latent variable) and a total of 22 observed variables were imported into the software Amos17.0 to build a model and tested for fit. The absolute fitting index and relative fitting index of the model do not fully meet the ideal requirements of fitting index. Through the release of the modified indices e10 $\leftrightarrow \mathrm{e} 11$, e5 $\leftrightarrow \mathrm{e} 6$, e8 $\leftrightarrow$ e9, the release of the modified index is based on the principle of reasonable interpretation of the structural equation model, and a gradual release is adopted to obtain a better-fitting model B. Specific indicators are shown in table 2.

Table 2 Model fitting index

\begin{tabular}{|c|c|c|c|c|c|c|c|}
\hline \multirow{2}{*}{} & \multicolumn{3}{|c|}{ Absolute fit index } & \multicolumn{4}{c|}{ Relative fit index } \\
\cline { 2 - 8 } & $\chi 2 / d f$ & GFI & RMSEA & AGFI & NFI & CFI & IFI \\
\hline Ideal value & $1-3$ & $\geq 0.9$ & $<0.1$ & $\geq 0.9$ & $\geq 0.9$ & $\geq 0.9$ & $\geq 0.9$ \\
\hline Model A & 2.303 & 0.864 & 0.08 & 0.820 & 0.718 & 0.813 & 0.818 \\
\hline Model B & 1.544 & 0.905 & 0.076 & 0.901 & 0.911 & 0.935 & 0.944 \\
\hline
\end{tabular}

Note: Model A is the initial model, while model B is the final model. 


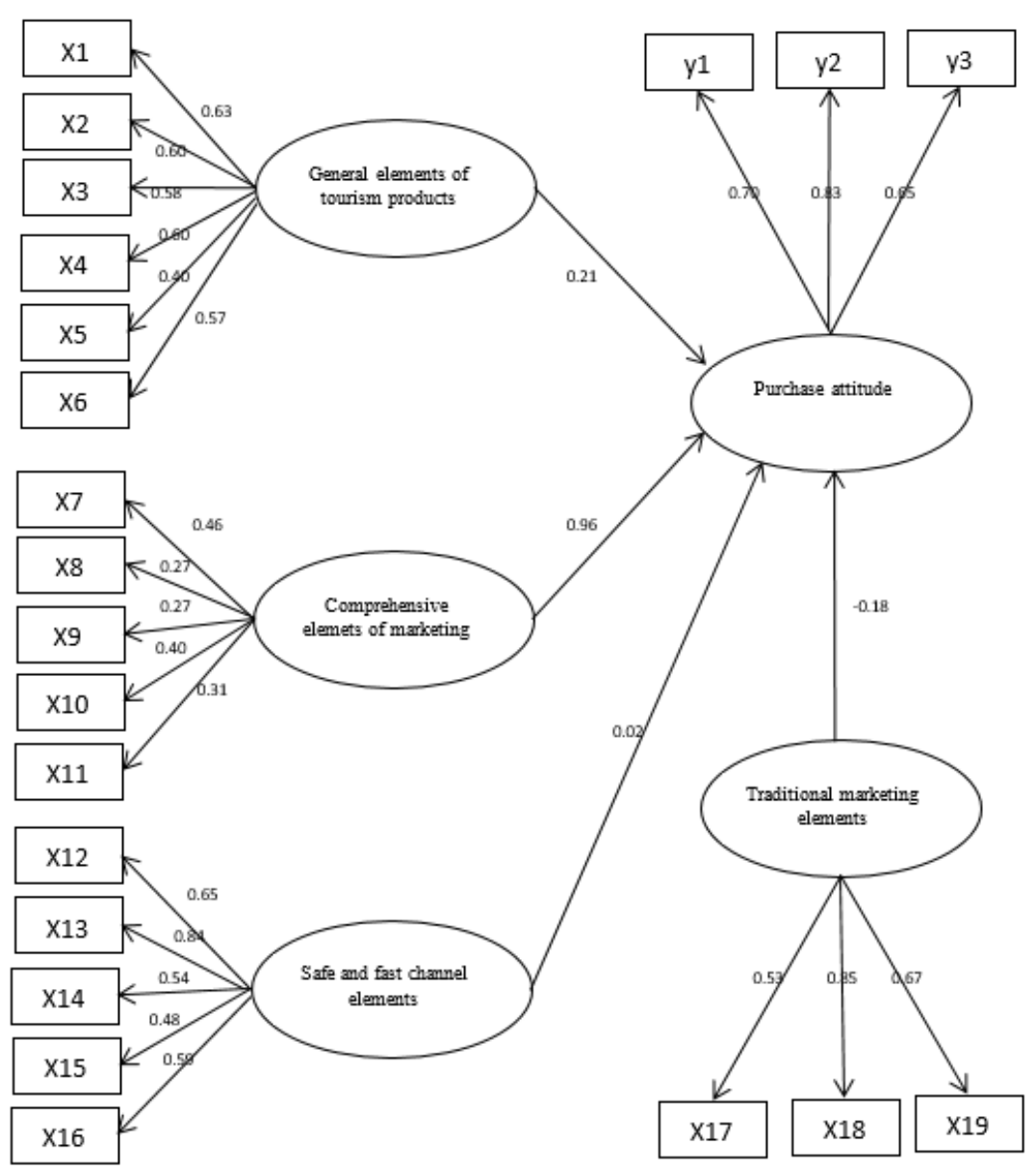

Figure 2 Structure model of online tourism product information attention and purchase intention

Table 3 Model standardization parameters

\begin{tabular}{|l|l|l|}
\hline & $\begin{array}{l}\text { Parameter } \\
\text { estimation }\end{array}$ & Result analysis \\
\hline General elements of tourism products -- > purchase intention & $0.21^{* *}$ & $\begin{array}{l}\text { Significantly } \\
\text { positive }\end{array}$ \\
\hline Comprehensive marketing elements --> purchase intention & $0.96^{* * *}$ & $\begin{array}{l}\text { Significantly } \\
\text { positive }\end{array}$ \\
\hline Channel safety and fast elements --> purchase intention & 0.02 & Weak positive \\
\hline Elements of traditional marketing --> purchase intention & $-0.18^{*}$ & $\begin{array}{l}\text { Significant } \\
\text { negative }\end{array}$ \\
\hline
\end{tabular}

Note: *** means $\mathrm{P}<0.001 ; * *$ means $\mathrm{P}<0.01 ; *$ means $\mathrm{P}<0.05$

\subsection{Fitting results and analysis}

As shown in table 3 , the relationship between the four dimensions of online tourism route product information concern and online purchase intention of tourists is consistent with the hypothesis. Among them, the comprehensive marketing elements have the largest purchase intention influence $\left(0.96^{* * *}\right)$, followed by the general tourism product elements $\left(0.21^{* *}\right)$, the traditional marketing elements $\left(-0.18^{*}\right)$, and finally the channel safety and shortcut elements (0.02). It shows that the generation of tourists' purchase intention depends largely on the comprehensive elements of marketing and the general elements of tourism products. The traditional marketing elements will significantly negative influence purchase intention.

(1) General elements of tourism products have strong positive influence on online purchase 
intention of tourists

Any consumer pays close attention to the product before purchasing. The product often determines the consumer's purchase attitude and intention. Tourism products are no exception, and the general elements of tourism products are significantly affecting online purchase intention. In addition, factor loads are shown in figure 2, it is known that the number of days in the tourism route (0.63), the price of the tourism route (0.60), and the brand of the tourism route supplier $(0.60)$ are ranked in the top three. It shows that the main factors for tourists to generate purchase intention are the appropriate schedule days, prices and brand suppliers. Many scholars have discussed the influence of price and brand supplier factors on online products' purchase intention, but the number of schedule days of tourist routes is a unique attribute of online tourism route products. Due to the limited time constraints on tourists' travel activities, this attribute is the strongest for online purchase intention of tourists. This attribute reflects the difference between online tourism route product's influence on consumers' purchase intention and general product attributes. Therefore, tourism enterprises should focus on optimizing the three factors of route schedule days, route price and route supplier in the general elements of tourism products.

(2) The comprehensive factors of marketing have significant positive influence on online purchase intention

The comprehensive marketing elements have a very significant positive influence on tourists' online purchase intention. From the factor loading in figure 2, it can be seen that beautiful resource pictures have the largest influence on tourists (0.46), followed by the number of purchasers $(0.40)$. When buying online tourism route products, tourists are often attracted by beautiful pictures, because pictures mean the products that tourists are likely to experience in the future. Tourists have the characteristics of conformity, and the number of consumer will subconsciously influence the online purchase intention. The conclusion of this research are consistent with the findings of scholars such as Ning Lianju [34] and Wang Qiuzhen [38]. Therefore, for online travel companies, optimization of beautiful pictures, layout, and number of purchases are the key marketing strategies.

(3) Channel security and fast factors have weak positive influence on online purchase intention of tourists

With the improvement of Internet technology, Most websites can protect consumers' interests. Website security has no decisive effect on online purchase intention, but it is still one of the factors that tourists consider when buying online. From the factor loading in figure 2, the popularity of the website (0.84), the security of the website (0.65), and the brand tourism resources $(0.59)$ are the most influential for tourists to purchase travel route products online. Trust in travel route products, thus influence tourists' online purchase intention.

(4) Traditional marketing elements have significant negative influence on online purchase intention of tourists

Traditional marketing elements include low and medium price and rich information. The marketing of traditional tourism products is often to set a lower price, meanwhile, the large scenic spots are divided into several small scenic spots to introduce to tourists in detail, so that tourists feel that the value of the goods exceeds the value. When the dishonest behavior of tour operators is exposed, the negative influence of traditional marketing elements on online purchase intention is presented. From the factor loading in figure 2, tourists' online purchases are becoming more and more rational. Low prices (0.85), medium prices (0.67), and decomposed travel route information (0.53) will limit tourists' willingness to purchase travel route products online. Therefore, it is an important marketing strategy for online tourism route product marketing in the future to set a reasonable price and improve the product quality.

\section{Conclusion}

(1) Tourists' information concern about online tourism route products is expressed in four dimensions. They are general factors of tourism products, comprehensive factors of marketing, channel safety and efficiency factors, and traditional marketing factors.

(2) The comprehensive marketing elements have a very significant positive influence on tourists 
'online purchase intention, the comprehensive marketing factor is important influence factor for tourists' online purchase. Through the beautiful tourism pictures, the agglomeration effect brought by a large number of buyers can greatly improve tourists' online purchase intention. General factors of tourism products have a strong and significant positive influence on online purchase intention of tourists. Under the constraints of tourists' time and money, it will be more popular to plan the appropriate itinerary days, set a reasonable price, and supply the tourism itinerary products by brand suppliers. Therefore, tourism e-commerce enterprises should cooperate with brand suppliers to design tourism routes that meet the needs of tourists according to their working and rest schedules.

(3) Traditional marketing elements have a significant negative influence on tourists' online purchase intention. The strategy of attracting tourists to buy online at low prices has no longer adapted to market demand. So, we should improve the quality of tourism routes and attract tourists with reasonable prices and high-quality products.

(4) Compared with the previous study on tourism consumption intention, this study is more microcosmic, which helps the online tourism route marketing and sales of tourism enterprises. In addition, the research on online tourism product information is more about designing online tourism route product information concern indicators from a marketing perspective. Although this study explored the influence factors of online tourism route product purchase intention, it did not specify the scale at which each influence factor should be controlled to be more popular with online tourists. This could be a further research direction in the future. For example, the price will influence tourists online purchase, but what kind of price is best for influence tourists to buy online? Supplier influence tourist online purchase intent, but what kind of supplier can influence tourist online purchase best? All of the above can be taken as the direction of further research.

\section{References}

[1] Chu R. (2001) What online Hong Kong travelers look for on airline /travel websites.International Journal of Hospitality Management, 20(1), 95-100.

[2] Raitz K, Dakhil M. (1989) A note about information sources for preferred recreational environments. Journal of Travel Research, 27(1), 45-49.

[3] Choi S, Lehto.1 X Y, Oleary J T. (2007) What does the consumer want from a DMO website? A study of US and Canadian tourists' perspectives. International Journal of Tourism Research, 9(2): 59-72.

[4] Li Junyi, Yang Min. (2010) A study on the behavior of information search of Xi'an Domestic Tourist network. Economic geography, 30 (7), 1212-1220.

[5] Hu Xingbao, Su Qin, et al. (2012) A study on motivation and content of online tourism information search of domestic tourists. Journal of Tourism, 27 (11), 105-112.

[6] Zhou Dan. (2011) Research on the impact of online negative word of mouth on consumers' online travel booking decisions. Guangzhou: South China University of Technology, 1-7.

[7] Akdeniz, B., Calantome, R.J. \& Voorhees, C.M. (2013) Effectiveness of marketing cues on consumer perceptions of quality: The moderating roles of brand reputation and third-partyinformation. Psychology \& Marketing, 30(1), 76-89.

[8] G. Alok, Su. Bochiuan, W. Zhiping. (2004) Risk Profile and Consumer Shopping Behavior in Electronic and Traditional Channels. Decision Support Systems, 38, 347-367.

[9] Zheng Shaocheng. (2009) The effect of online tourism product discount types and magnitude: a study of corporate image and service assurance as interference variables. Jilin, Jilin University.

[10] Yao Qian. (2015) Research on the influence of price and seller's reputation on consumers' online purchase decision under different product involvement levels. Hangzhou, Zhejiang University. 
[11] Wang L., Law R., Guillet B.D., et al. (2015) Impact of hotel website quality on online booking intentions: e Trust as a mediator. International Journal of Hospitality Management, 47, 108-115.

[12] Chen Binbin. (2016) A study on tourists' perception of online consumption security. Chongqing: Chongqing Normal University, 1-60.

[13] Woo Gon Kim, Dong Jin Kim. (2004) Factors affecting online hotel reservation intention between online and non-online customers. Hospitality Management, (23), 381-395.

[14] Yin Ying. (2011) Research on factors affecting customer booking intention of official website of hotel. Guangzhou: South China University of Technology, 1-64.

[15] Liu Yan, Pu Bo, Guan Zhenzhong. (2016) The influence of online experience of tourism consumers on re booking from the perspective of immersion theory. Journal of Tourism, 9 (31), 85-95.

[16] Wang Sili. (2011) Research on the relationship between customer perceived risk, perceived value and relationship quality in the process of online travel booking. Shandong, Shandong University, 1-113.

[17] Peng Maojuan. (2016) Research on the influence of website quality of budget hotels on consumers' online booking intention. Guangzhou, South China University of Technology, 1-86.

[18] Wong J., Law R. (2005) Analyzing the intention to purchase on hotel websites: a study of travelers to Hong Kong. International Journal of Hospitality Management, 24, 311-329.

[19] Kim W.G., Ma X.J., Kim D.J. (2006) Determinants of Chinese hotel customers' e-satisfaction and purchase intentions. Tourism Management, 5(27), 890-900.

[20] Liu J.N.K., Zhang E.Y. (2014) An investigation of factors affecting customer selection of online hotel booking channels. International Journal of Hospitality Management, 39, 71-83.

[21] Zhang Meng, Zhang Guangyu, Ye Zuoliang. (2011) Research on the influence of online information on online hotel reservation -- based on the analysis of online hotel reservation data of trip. Journal of Tourism, 26(7), 79-84.

[22] Zhu Jingyan. (2014) Research on online booking behavior of travel website users. Shanghai: East China Normal University, 1-86.

[23] Wu Kai. (2004) Operations research problems in the design and optimization of tourism routes. Tourism Science, 18 (1), 41-45.

[24] Li Yuan, Ding Yanjie, Wang De. (2006) Study on the tourism route design method of scenic spots with time constraints and spatial behavior characteristics. Tourism Tribune, 9 (31), 50-60.

[25] Sun Yong, Shi Chunyun et al. (2016) Characteristics of tourism route network and spatial structure in Yunnan Province. Human Geography, 147 (1), 147-160.

[26] Liu Hongying, Wei Liliu, Zhang Juan. (2012) Study on the structure characteristics of regional tourism flow network based on tourism routes. Human Geography, 126 (4), 131-136.

[27] Huang Xiaoting, Li Minxuan, Zhang Haiping. (2016) Research on the evaluation of tourism spatiotemporal behavior based on GPS data. Journal of Tourism, 9 (31), 40-49.

[28] Liu Limin, Zhong Linsheng, et al. (2017) Network spatial characteristics and influencing factors of self-service tour and team tour routes in Qinghai Province. Economic Geography, 12 (6), $1-12$.

[29] Guo Anxi, Guo Yingzhi, et al. (2018) An Empirical Study on the influence of tourists' perceived value on their intention to revisit. Journal of Tourism, 1 (33), 63-73.

[30] Zhu Haiyan, Tian Linlin. (2017) Research on the impact of online information on online booking of star hotels and economy hotels in Xi'an city-Taking Ctrip data as an example. Value 
Engineering, 10 (2), 3-6.

[31] Lou Zaifeng. (2016) Analysis of influencing factors of online travel consumer purchase decision. Business Economics Research, 12 (2), 38-40.

[32] Kim, H.W., Xu, Y., \& Gupta, S. (2011) Which is more important in Internet shopping, perceived price or trust? Electronic Commerce Research and Applications, 11(3), 241-252.

[33] Jiang Xiao, Du Rong, Guan Xi. (2010) Empirical study on the influence of online word-of-mouth on consumers' purchasing decisions. Journal of Information, 29 (9), 200-203.

[34] Wang Qiuzhen, Yao Qian, Ye ing. (2014) Research on the influence mechanism of price discount and number of buyers on consumers' impulse purchase intention under the situation of online group purchase. Journal of Management Engineering, 4 (28), 37-47.

[35] Song Zhijie, Tang Xiaoli. (2016) Research on the influence of price and evaluation on consumers' online purchase decision -- analysis based on eye movement experiment. Enterprise Economics, 10 (434), 71-77.

[36] Peng Liang, Xiao Minghui. (2011) Analysis of consumer trust in group buying websites based on AHP fuzzy method. Consumer Eonomy, 27 (5), 62-65.

[37] Liao Chenglin, Gong Xiaoyan, Li Yi. (2012) An Empirical Study on the influence of website perception and trust of new customers on their online purchase behavior. Technology and Economy, 31 (1), 16-21.

[38] Ning Lianju, Zhang Xinxin. (2011) An empirical study on the influencing factors of impulse purchase intention of consumers in online group buying. Journal of Fujian Normal University (PHILOSOPHY AND SOCIAL SCIENCES EDITION), 6, 13-18. 